\title{
Programa para un posgrado futuro ${ }^{1}$
}

2. Raúl Antelo / Universidade Federal de Santa Catarina - CNPq / antelo@iaccess.com.br

\section{Incógnitas y revesadas}

Así como las ciencias experimentales europeas pudieron desarrollarse en la Modernidad bajo el paraguas de un libro-fantasma enciclopédico, Peter Sloterdijk nos recuerda que la tarea de los lingüistas y especialistas en literatura fue siempre la de arduamente elaborar el exterior de esas lenguas, en contacto con un multiverso semiótico de enorme diversidad, compuesto de, al menos, otras 6000 congéneres y sus correlativas mitologías, religiones, ceremonias, rituales, artes y gestualidades. A la vista de tamaña multiplicidad, que se burla de cualquier sinopsis, se desvanece el sueño de un hiperlenguaje omniintegrador, aún más si nos atenemos a la Sinopsis del artista alemán Gerhard Richter, uno de los más acabados representantes de la desnaturalización del tableau y su reconversión en table, es decir, en mesa de operaciones y montajes anacrónicos, como diría DidiHuberman. $^{2}$

En efecto, en 2000, Richter inaugura Übersicht, una exposición que se quiere también un Survey, una mirada abrazadora, de su propia obra. En ella nos propone, de hecho, un panorama de las artes y el pensamiento mundiales en que sólo encontramos tres parcos representantes de las culturas ibéricas: Cervantes, Calderón y Borges. Por ello, en el proceso esferopoiético americano, el estudio de las letras se enfrentó, tradicionalmente, a dos estrategias diferentes para orientarse en tan variada profusión neobabélica: una, la imposición a la fuerza de las letras de dominio colonial como lenguas universales de circulación, cosa que, al menos parcialmente, consiguieron el inglés, el español y el francés; otra, la penetración de cada una de las literaturas en concreto por la voz traducida de los nuevos seńores. En la primera perspectiva, que es la más fuerte en la Argentina moderna (1880-1930), el historicismo europeo no fue sino el crepúsculo de la era terrestre de la globalización en que, frente a la inexistencia de un relato centralizado de la obra conquistadora colectiva, sólo funcionó una serie abierta de proyecciones nacionales en lo total: una historia universal de España, una historia universal de 
Inglaterra, una historia universal de Francia, una historia universal de Portugal, dispersión de las expansiones políticas que a su vez se replicó en las potencias misioneras cristianas, ajenas a un plan maestro eclesiológico, y en que los jesuitas, los franciscanos o los dominicos trabajaron sus respectivos imperios universales salvacionistas, como los llamaba Darcy Ribeiro, cada uno en lo suyo. Menéndez Pelayo, cuando arma su historia española de la literatura hispanoamericana en el marco del Iv centenario del descubrimiento, estipula el corte epistemológico con limpieza quirúrgica.

Trátase sólo de la poesía castellana en América, quedando excluida con ello otra poesía no castellana de lengua, aunque pueda ser calificada de espańola en el sentido más tradicional y etnológico de la frase, es a saber: la opulenta poesía brasileńa, que es quizá la más americana de toda América sin que por eso deje de ser esencialmente portuguesa. Hoy parece algo decaída de su antiguo esplendor, pero le basta para su gloria con lo que de ella conoció y reveló a Europa Fernando Wolf en I863. No nos ha parecido bien ni retocar su trabajo, ni menos mezclar lenguas distintas en una misma obra.

\section{Por ello Menéndez Pelayo prescinde}

de la poesía indígena en lenguas americanas, anterior o posterior a la conquista. Extraños nosotros de todo punto al estudio del Nahuatl, del Otomí, del Tarasco, del Mixteco, del Maya, del Otlateco, del Quichua, del Aymara, del Guaraní y de tantas otras lenguas todavía más incógnitas y revesadas [subrayado por mí], nada hubiéramos podido hacer sino repetir superficialmente lo que han consignado en tratados especiales los que pasan por entendidos en estas arduas materias. Sea cual fuere la antigüedad y el valor de los pocos y oscuros fragmentos literarios que de esas lenguas primitivas quedan (...), su influencia en la poesía española de América ha sido tan escasa, o más bien tan nula (...), que la historia de esa poesía puede hacerse en su integridad prescindiendo de tales supuestos orígenes y relegándolos al estudio y crítica del filólogo. Así lo han hecho los críticos americanos, aun los más conocedores de las lenguas indígenas, y así lo haremos nosotros, prescindiendo de la erudición de segunda mano que hubiéramos podido granjear con pequeñísimo esfuerzo. La poesía americana de que vamos a tratar no es de las elegías del rey de Tetzuco, Netzahaulcoyotl, ni la del Ollantay, drama quichua no anterior al siglo XvıII, sino la que llevaron a América los colonos españoles y conservan sus descendientes. $(3 \mathrm{I} 4)^{3}$

El objetivo explícito de Pelayo era pues rearmar un orden global de receptividad para esa literatura informe, porque a su juicio, sólo

Dos lenguas hay, entre las que modernamente se hablan en el mundo, que pueden aspirar en cierto grado a esta misma singular excelencia de las lenguas clásicas. Entre las dos se reparten el número mayor de las gentes civilizadas, y con ambas puede darse la vuelta al planeta con seguridad de ser entendida en todas partes. Son las lenguas de los dos pueblos colonizadores que nos presenta la historia del mundo moderno: representantes el uno de la civilización de 
la Europa septentrional, del espíritu germánico más o menos modificado, del individualismo protestante; el otro del genio de la Europa meridional, del organismo latino y católico: pueblo que en los días de su grandeza parece que sentía resonar en sus oídos, más enérgicamente que ninguno de sus hermanos de raza, el Tu regere imperio populos, Romance, memento. América es o inglesa o española: en el extremo Oriente y en los Archipiélagos de Oceanía también coexisten, aunque en muy diversa proporción, entrambas lenguas. La literatura británica enriquece su caudal propio, no sólo con el caudal de la literatura norteamericana, sino con el de la que ya empieza a cobrar bríos en Australia. Nosotros también debemos contar como timbre de grandeza propia y como algo cuyos esplendores reflejan sobre nuestra propia casa, y en parte nos consuelan de nuestro abatimiento político y del secundario puesto que hoy ocupamos en la dirección de los negocios del mundo, la consideración de los cincuenta millones de hombres que en uno y otro hemisferio hablan nuestra lengua, y cuya historia y cuya literatura no podemos menos de considerar como parte de la nuestra. (6-7)

Aún hoy, la Real Academia española pide unidad en la diversidad, cuando tal vez lo más sensato fuera exigir valoración política de lo heterogéneo (Gruzinski), en detrimento del festivo mercadeo de lo diverso.

\section{Avatares de la diferencia}

Pero si ese historicismo hispánico anuncia, de hecho, el crepúsculo de la era terrestre de la globalización, porque a su petulancia podríamos responder con lo que Derrida nos decía en El monolingüismo del otro («Oui, je n’ai qu’une langue, or, ce n'est pas la mienne», en que or es tanto alternativa, contrariedad o, incluso, lo que los españoles buscan en América, el oro), debemos su completa demolición a Nietzsche, cuya estrategia de oposición entre arte y ciencia es central al debate, una vez que, para el autor de Aurora, que anuncia el mal de aurora o Maldoror, el progresivo conocimiento del origen sólo demuestra la total insignificancia del origen (aforismo 44). Ante esa falta de fundamento de la verdad, que abre la puerta a los pensadores posfundacionales (Lacan, Badiou, Nancy, Laclau), el artista aparece como alguien que, con relación a la verdad, tiene una moral más débil que la del pensador; pero ya que, en el mundo moderno triunfa lo fantástico y lo mítico como experiencias de choque de la realidad factual, confrontadas a la imaginación, las fantasías y las identificaciones antropomórficas (Díaz Quiñones), entonces, de esa actividad de embestida directa de lo exterior, de lo «dado», como reza la emblemática instalación de Duchamp, es por lo tanto de la imaginación misma que se origina la presión (la impresión, la huella) de las emociones, lo cual está en sintonía con la teoría nietzscheana de la tragedia, donde la visión apolínea era sustancialmente un modo de aplacar la fuerza del impulso dionisíaco, de disminuir su caos lacerante, aunque luego esa conexión entre arte y emociones superase holgadamente la mera función catártica e higiénica, para ambicionar horizontes más altos de cabal conocimiento.

En efecto, como lo sabía muy bien Flávio de Carvalho o bien todos aquellos que Hal Foster estudió en Dioses prostéticos, el artista, precisamente porque es psi- 
cológicamente infante $y$, antropológicamente, un vestigio de épocas atravesadas por lo arcaico y lo mítico, vive también las pasiones y emociones a la manera de los nińos y los primitivos, con violencia e impetuosidad y esa impetuosidad con la que vive sus propias emociones no es sólo una señal del carácter de exceso que el arte manifiesta, sino también de su conexión a otras formas del exceder, tales como la excedencia y la excepción. ${ }^{4}$ Outra travessia ha dedicado un número monográfico a ese tópico, ${ }^{5}$ pero baste decir que excedente es el arte precisamente por su forma de exceso: si los griegos inventaron fábulas, con las que disfrazaban y trasfiguraban la realidad, ese impulso de inventar máscaras, que se repite del simbolismo a las vanguardias, tendió a volverse independiente de sus funciones originarias y a convertirse en una tendencia autónoma a la fabulación y el delirio, a partir del surrealismo hasta el situacionismo y más. ${ }^{6}$ La excedencia del arte es tal incluso respecto de las otras formas espirituales, como la religión, la moral o la metafísica, que Nietzsche ya consideraba cosas del pasado.

Como destaca Gianni Vattimo, ninguna de las formas del pasado moral-metafísico de la humanidad, que Nietzsche supo desenmascarar tan bien, tiene una posición tan ambigua y ambivalente como el arte. La literatura en particular es, sí, un pasado, pero es también un futuro, si tomamos en cuenta la afirmación de que no hay felicidad sin placer del absurdo, sin travestimiento artístico, sin invención, sin máscara, o sea sin lenguaje. En este sentido, el arte excede el destino de su desaparición, que es propio de las formas de la mentira metafísica, y lo excede precisamente porque, a diferencia de ellas, es juego y excepción. En suma que, contra las interpretaciones de tipo heideggeriano, que entienden la voluntad de poder como la extrema manifestación de la organización tecnocrática del mundo, convirtiéndolo al mismo hombre en objeto de planificación total, destacar el significado de la voluntad de poder como arte significa, al contrario, subrayar la voluntad de potencia como voluntad de chance contingente y aleatoria (según Bataille), es decir, como estrategia esencialmente desestructurante. Es éste el punto sobre el que se debe buscar la conexión entre Nietzsche y la literatura del siglo $\mathrm{xx}$, que tradujo su lección en términos creativos, como Ernst Behler mostró en sus Confrontations: Derrida, Heidegger, Nietzsche.

En efecto, hay que recordar que, para Derrida, hay dos lecturas de la interpretación, de la estructura, del juego o del signo. O bien se busca descifrar un origen y una verdad que escapa del orden del juego y del signo y vive la necesidad de interpretación como un exilio; o bien, descartando el origen, se acepta el juego y se quiere ir más allá del humanismo, entendiendo como hombre el ser que buscó, por medio de la metafísica y la ontoteología, aislar la totalidad de su historia, la presencia absoluta, o sea, el final del juego, para decirlo con Cortázar. La primera perspectiva es la heideggeriana; la segunda, mediada por Nietzsche, es la del mismo Derrida.

Por lo tanto, el arte, que toma como modelo la voluntad de chance, no es pensado en términos de gran estilo, de altas literaturas o de forma cerrada, sino como impetuosidad de pasiones, preferencia por la fabulación inmanente, pul- 
sión, arrogancia del artista en hacerse pasar por genio o imposición a las cosas inertes de aleatorias configuraciones que nada conservan de la forma clásica. El actual retorno del realismo, por ejemplo, debería ser estudiado entonces más por esa vía de retorno, que como realismo, es decir, más como reinstalación de las aventuras de la diferencia que como tozuda victoria póstuma de Lukács. La danza de Zarathustra que ya podemos reconocer en Loie Füller, tan admirada por Mallarmé y Rubén Darío, no es por la misma razón un hecho apolíneo (forma pura, perfección y transparencia, estabilidad, orden y simetría), sino caos y desenfreno dionisíaco, atravesados, a veces, por la ironía, figura que poco tiene de apolínea. Paul Valéry, que indagó las relaciones entre el alma y la danza, supo ver, antes de Bataille, que la verdad es informe. O sea que la voluntad de chance no es voluntad de forma, de mímesis definitiva, y, por lo tanto, de dominio, sino que, al elaborar mecanismos emocionales que ponen en movimiento la vida emotiva, la aisthesis, tal como la investigan Maurizio Ferraris o Jacques Rancière, es voluntad de chance y así revela su carácter desestructurante. Lo decía Borges en I940:

En aquel ruidoso y casi perfectamente olvidado volumen — Degeneración - que tan buenos servicios prestó como antología de los escritores que el autor quería denigrar, Max Nordau vio en el carácter fragmentario de las obras de Nietzsche una demostración de su incapacidad para componer. A ese motivo (que no es lícito excluir y que no es importante) podemos agregar otro: la vertiginosa riqueza mental de Nietzsche. Riqueza tanto más sorprendente si recordamos que en su casi totalidad versa sobre aquella materia en que los hombres se han mostrado más pobres y menos inventivos: la ética.

Excepto Samuel Butler, ningún autor del siglo xIx es tan contemporáneo nuestro como Friedrich Nietzsche. Muy poco ha envejecido en su obra, salvo, quizás, esa veneración humanista por la antigüedad clásica que Bernard Shaw fue el primero en vituperar. También cierta lucidez en el corazón mismo de las polémicas, cierta delicadeza de la invectiva, que nuestra época parece haber olvidado. (I)

El juicio, que vale para Nietzsche pero podríamos extenderlo a Blanchot, nos muestra que los valores éticos, por lo tanto, no son sino posiciones estratégicas de la voluntad de poder, tanto de los fuertes como de los débiles, lo que sintoniza con la lectura hegeliana de Kojève, es decir, con la circularidad entre amo y esclavo, con el traidor y héroe. El macedoniano «todo se ha escrito, todo se ha dicho, todo se ha hecho», que leemos en el «Prólogo a la Eternidad» (1936-1938) del Museo de la Novela de la Eterna, anticipa, como sabemos, el aleph borgiano. Eterno retorno y voluntad de poder revelan así un fuerte carácter selectivo, que funciona como principio de desestructuración de las jerarquías, ya que eterno retorno no quiere decir que allí no existe el tiempo lineal, sino que existe la circularidad del todo. «El Sur» (I953) de Borges repite el Martín Fierro (I872); "História sem data» (I92I) de Mário de Andrade repite Avatar (I856) de Théophile Gautier; "El triunfo de Calibán» (I898), de Rubén Darío, como más tarde el poco recordado Calibán de Aníbal Ponce («Ariel o la agonía de una obstinada ilusión», 1938) o el más eviden- 
te Calibán (I97I) de Fernández Retamar repiten La tempestad (I623) de William Shakespeare. Pero la repetición en literatura nunca reitera la voz o la tradición para refrendarlas, sino para meditar y diferirlas. La repetición es diferencia. Y voluntad de chance tampoco quiere decir que no hay valores, que anything goes, sino que sólo se reconoce la acción de fuerzas enfrentadas. Tomemos, a título de ejemplo, el caso de las relaciones entre las literaturas hispanoamericanas y la brasileña, ${ }^{7}$ un buen campo para probar el futuro de la investigación en literatura latinoamericana.

\section{Falsos cognatos}

A lo largo del siglo xIx y la primera mitad del siglo xx, algunas antologías, contemporáneas formas espectaculares de la Wunderkammer ${ }^{8}$ medieval, abren discreto espacio para esas alianzas, tales como la América literaria (I883), de Francisco Lagomaggiore o las Joyas poéticas americanas (I897) de Carlos Romagosa, ${ }^{9}$ hasta que recién en el 68, el Congreso Cultural de La Habana traza su propio Übersicht, el Panorama de la Actual Literatura Latinoamericana. Ya en la posdictadura, en el discurso crítico de la democratización, es bueno recordar que Noé Jitrik siempre incluyó a la literatura brasileña en sus cursos de latinoamericana, como atestigua Las Maravillas de lo Real. Literatura Latinoamericana (200o). De ese gesto provienen críticos muy activos hoy como Gonzalo Aguilar, autor del pionero Poesía concreta brasileña: las vanguardias en la encrucijada modernista (Rosario, Beatriz Viterbo, 2003), quien junto a Florencia Garramuńo, autora de La experiencia opaca. Literatura y desencanto (20II); Modernidades Primitivas. Tango, Samba y Nación (2007) o Genealogías Culturales. Argentina, Brasily Uruguay en la novela contemporánea (1997), es responsable no sólo por la recreación de la cátedra de literatura brasileña en la UBA, sino por la colección Vereda Brasil de Corregidor y por la emergencia de otros talentos más jóvenes aún, como Adriana Amante, autora de una tesis monumental, Poéticas y politicas del destierro. Argentinos en Brasil en la época de Rosas (2010), o Mario Cámara, hoy scholar en Princeton, investigador de la contracultura pos-68 en Cuerpos paganos (20II). Tales esfuerzos se institucionalizan en la maestría en estudios brasileños de la Universidad de San Andrés, con Garramuño y Cámara, o en el doctorado en estudios latinoamericanos comparados de la unTref, bajo las órdenes de Daniel Link. Allí se también se desempeña Adriana Rodriguez Pérsico, cuyos Relatos de época: una cartografía de América Latina (I880-1920), distinguido por la Casa de las Américas, ensaya ese diálogo entre ambas esferas. En clave etnológica, recordaría también a un profesor de la Universidad de Córdoba, Gustavo Sorá, y su libro Traducir el Brasil. Una antropología de la circulación internacional de ideas (2003).

Sin embargo, en ámbito internacional, cabe subrayar que la mayoría de los ensayos de articulación entre, digamos, la poesía brasileña y sus congéneres latinoamericanas tiene tronco anglosajón: Víctor Valenzuela y su Contemporary Latin American Writers (I97I); Günther W. Lorenz y su Literatur in Lateinamerika (1965); el antológico The Pinguin Book of Latin American Verse (I96I) o la obra 
de Mike Gonzalez y David Trece, The Gathering of Voices. The 2oth. century poetry of Latin America (1992), lo cual pone sobre la mesa una peculiar contradicción: es, grosso modo, en la universidad americana, donde las fuerzas evadidas de la historia mundial se dedican precisamente a redescubrir para ellas la auténtica historia global. Y esa tendencia acaba, en los días actuales, desinteresándose por la relación entre las literaturas nacionales, es decir, las literaturas hispanoamericanas y su conexión con la brasileña, entre sus lenguas, y, en su defecto, se abre el debate sobre las relaciones entre letra e imagen. Pongo dos ejemplos: Fotografia e Império: paisagens para um Brasil moderno de una profesora de la Universidad de California en Berkeley, Natalia Brizuela (São Paulo, Companhia das Letras/ Instituto Moreira Salles, 20I2); o The Itinerant Languages of Photography, la exposición de dos profesores de Princeton, Eduardo Cadava, coautor del famoso Who comes after the subject; ${ }^{10}$ y Gabriela Nouzeilles, a quien todos recuerdan por Ficciones somáticas o La naturaleza en disputa. Retóricas del cuerpo y el paisaje. De hecho, en The Itinerant Languages of Photography, actualmente en exhibición en el Princeton University Art Museum, para cuyo catálogo (Yale University Press, New Haven/ London, 2013) colaboran además Joan Fontcuberta, Valeria González, Thomas Keenan, Mauricio Lissovsky y John Mraz, leemos en un apartado titulado «The Invention of Brazil», que

Photography was instrumental in the creation of a set of images that helped define modern Brazil as a tropical landscape and a multiethnic society. It served to represent its nature and its peoples, and it also offered a visual narrative of national modernization through images of new buildings and roads, public parks, and busy ports. Revert Henrique Klumb's photographs of Petrópolis — the modern city that was built for the emperor though he never lived there - and Marc Ferrez's gorgeous archival images of wider Brazil belong to the collective enterprise of capturing a nation in images. (IO4)

La fotografía, nombre paradójicamente acuñado por un brasileño de adopción, el campinero Hércules Florence, ha venido a ocupar, a través de su icnología y no de la iconografía, el lugar de la voz de un lenguaje no conocido, como el portugués, y que siempre funcionó como obstáculo, lo cual es un efecto indeseado pero coherente del final del juego que descarta y postula lo poshumano como imposición a las cosas inertes de aleatorios montajes. ${ }^{11}$ Pero esa función celebratoria de lo material no deja de postular asimismo otra paradoja señalada por Emanuele Coccia: es a las cosas, en Occidente, a las que se les confía la historia, la fortuna, el futuro. Conservan el sentido, dan entidad a la memoria. ${ }^{12}$ Es a los libros y a las piedras ${ }^{13}$ a los que interrogamos acerca de identidades arcaicas. El uso dado a las cosas define pues hábitos, y éstos, a su vez, una etnología de la vida cotidiana y las formaciones sociales. Curiosamente, en nuestras más antiguas y prestigiosas religiones, cualquier cosa podía ser usada para cumplir un sacrificio ritual, mais surtout pas las cosas. Son los otros, los bárbaros entre los antiguos o los salvajes entre los extranjeros, los que pueden practicar el culto de las cosas, de modo que 
la cuestión de la fotografía inscribe decididamente nuestro problema, la relación entre las literaturas hispanoamericanas y la brasileńa, en la esfera de la cultura o, lo que es lo mismo, en la de la política. Los actuales estudios de intermedialidad y, en particular, la atención dispensada a los pioneros trabajos de Aby Warburg por estudiosos como Philippe-Alain Michaud, cuyo Aby Warburg et l'image en mouvement (1998) nos persuade de que esas fórmulas de sensibilidad aquí investigadas son imágenes de la imagen, nos retrotraen a algo que Agamben ya había planteado inequívocamente:

Le immagini sono, pertanto, un elemento decisamente storico; ma, secondo il principio benjaminiano per cui si dà vita di tutto ciò di cui si dà storia (e che qui si potrebbe riformulare nel senso che si dà vita di tutto ciò di cui si dà immagine), esse sono, in qualche modo, vive. $(2007: 54)^{14}$

Con lo cual el filósofo nos dice lo mismo que Jean-Luc Nancy, o sea, que el tiempo de la globalización sólo puede ser pensado como un tiempo-con, un tiempo no-cronológico sino anacrónico. Y esa vida que se concede a las imágenes es la nuda esistenza biologica de la que Agamben ya hablaba, en 1970, en El Hombre sin contenido. Pero en Signatura rerum, su libro sobre el método, el mismo Agamben amplía el concepto y nos advierte que la manera menos creativa de leer los desdoblamientos de Mnemosyne consiste en verlos, justamente, como un repertorio iconográfico, en que la cuestión relevante sería el origen y evolución de un tema, como suponía Pelayo. Eso es historicismo. Es, a lo sumo, Curtius y el linaje de los discípulos británicos de Warburg, como Gombrich y Panofsky. Lo instigante, en cambio, es reparar que ninguna imagen es original, pero ninguna de ellas es tampoco réplica o pasiva reproducción de una matriz, de lo que se concluye ser indecidible el estatuto de creación y acto, original y performance, porque las imágenes serían híbridos de arquetipo y fenómeno. He allí lo icnológico, el saber de los vestigios. "Ogni fotografia è l'originale, ogni immagine costituisce l'arché, è, in questo senso, arcaica», pero la imagen misma "non è né arcaica né contemporanea, è un indecidibile di diacronia e sincronia, unicità e molteplicità» (2008:3I). El paradigma, en una palabra, está vacío y lo que busca es «encontrar un cuerpo y una carne, como su inútil habladuría, antes de sumirse para siempre en el silencio» (Bergamín en Agamben 200r:87).

\section{El objeto polémico}

Analía Gerbaudo, profesora de la Universidad Nacional del Litoral, donde dirige el doctorado en Humanidades, fijó, en artículo reciente, los varios momentos de la posdictadura argentina. Habla Gerbaudo de cinco momentos, signados por la irrupción de distintos «acontecimientos». El primero está marcado por la promesa de justicia y participación ciudadana, a través del Juicio a las Juntas Militares, que a despecho del consenso redemocratizador, es un tiempo signado por la proliferación de polémicas. El segundo momento es su quiebra por 
desilusión con las leyes de Punto Final (1986) y Obediencia Debida (I987). El tercer momento, según Gerbaudo, está atravesado por una nueva discursividad sobre el horror, en que, como respuesta al cierre de los caminos de la justicia, se tramita una reparación, necesariamente in-completa, desde el arte. El cuarto momento es, como diría Andreas Huyssen, the great divide, el colapso de 200I, cuando el arte enfrenta la poscrisis (Andrea Giunta), que se traduce en ruptura de contratos institucionales. El último corte se produce en 2003 y marca el retorno de las polémicas que, como en los albores de la democracia, involucran a diferentes sectores. La exposición Imágenes e Historias. Argentina I848-20I0, curada por Diana Wechsler (Madrid, Fundación mapfre, 20Io; Buenos Aires, Centro Cultural Recoleta, 20II) lo materializa justamente en una emblemática fotografía: la bajada de cuadros del Colegio Militar. Las interminables controversias sobre los medios de comunicación, la reestructuración de la deuda o el matrimonio igualitario son algunos de los tantos hechos que generan nuevas polémicas que, en ámbito universitario, se traducen en la génesis de un nuevo tipo de intelectual académico, no ya el intelectual sartreano, barrido, sino ya por la redemocratización, ciertamente por el neoliberalismo, dando paso ahora al experto, atento a la minucia neutral y objetiva, razón por la cual Gerbaudo fecha «hacia 2003 el fin de la posdictadura», ya que el «reencantamiento ideológico con la política» y la «hiperestesia emotiva», como los define Carlos Altamirano, marcan un evidente cambio de época.

No es tan fácil trazar una periodización equivalente para Brasil, donde en gran parte prevalece aún el diagnóstico que, en I970, Roberto Schwarz trazara a pedido de Les Temps Modernes, es decir la combinación, en momentos de crisis, de lo moderno y lo antiguo, o en otras palabras, la convivencia de las manifestaciones más avanzadas de la integración imperial global y de la ideología nacional burguesa más arcaica y reaccionaria, centrada en el individuo, en la unidad familiar y en sus tradiciones. Esa coexistencia tiene carácter sistemático, aunque su sentido pueda variar en el tiempo. Mientras, antes del golpe de 1964, la modernización pasaba por las relaciones de propiedad y por la ideología, que deberían ceder ante la presión de las masas y de las necesidades del desarrollo nacional; tras el golpe, que, es bueno no olvidar, representa uno de los momentos cruciales de la Guerra Fría, se consolidó la derrota de esas respuestas por la confirmación de las formas más tradicionales y localistas de poder. De esa manera, argumentaba Schwarz, la integración capitalista, responsable por una inmediata modernización de la economía del país, tonificó y dio nuevos aires a la peculiar mezcla de arcaísmo ideológico-político indispensable para su estabilidad. De obstáculo y residuo, el arcaísmo pasó a instrumento intencional de la opresión más moderna, así como, de liberadora y nacional, la modernización se transformó en voluntaria y deliberada forma de sumisión (Schwarz 1992) ${ }^{15}$ La concentración cuasi monopólica de los medios de imaginación, es un ejemplo, no citado por Schwarz, pero que se desprende de su análisis. ${ }^{16}$ Más recientemente, al evaluar que la misma noción de sistema literario nacional y con ella la de formación o, incluso en sentido más 
amplio y simple, la misma noción de forma había colapsado, Schwarz ponderó que habría varias razones para ello, más concretamente, tres, que a falta de mejor rótulo, podríamos llamar la razón neoliberal, la neopopulista y la neocolonial:

Uma é de que ela (a formação), que é também um ideal, perdeu o sentido, desqualificada pelo rumo da história. A nação não vai se formar, as suas partes vão se desligar umas das outras, o setor «avançado» da sociedade brasileira já se integrou à dinâmica mais moderna da ordem internacional e deixará cair o resto. Enfim, à vista da nação que não vai se integrar, o próprio processo formativo terá sido uma miragem que a bem do realismo é melhor abandonar. Entre o que prometia e o que cumpriu a distância é grande.

Outra perspectiva possível: suponhamos que a economia deixou de empurrar em direçáo da integração nacional e da formação de um todo relativamente auto-regulado e auto-suficiente (aliás, ela está empurrando em direção oposta). Se a pressão for esta, a única instância que continua dizendo que isso aqui é um todo e que é preciso lhe dar um futuro é a unidade cultural que mal ou bem se formou historicamente, e que na literatura se completou. Nessa linha, a cultura formada, que alcançou uma certa organicidade, funciona como um antídoto para a tendência dissociadora da economia. Contudo vocês não deixem de notar o idealismo dessa posição defensiva. Toda pessoa com algum tino materialista sabe que a economia está no comando e que o âmbito cultural sobretudo acompanha. Entretanto, é preciso reconhecer que nossa unidade cultural mais ou menos realizada é um elemento de antibarbárie, na medida em que diz que aqui se formou um todo, e que esse todo existe e faz parte interior de todos nós que nos ocupamos do assunto, e também de muitos outros que não se ocupam dele.

Outra hipótese ainda: despregado de um projeto econômico nacional, que deixou de existir em sentido forte, o desejo de formação fica esvaziado e sem dinâmica própria. Entretanto, nem por isso ele deixa de existir, sendo um elemento que pode ser utilizado no mercado das diferenças culturais, e até do turismo. A formação nacional pode ter deixado de ser uma perspectiva de realização substantiva, centrada numa certa autonomia político-econômica, mas pode não ter deixado de existir como feição histórica e de ser talvez um trunfo comercial em toda linha, no âmbito da comercialização internacional da cultura. Enfim, ao desligar-se do processo de auto-realização social e econômica do país, que incluía tarefas de relevância máxima para a humanidade, tais como a superação histórica das desigualdades coloniais, a formação não deixa de ser mercadoria. E ela pode inclusive, no momento presente, estar tendo um grande futuro nesse plano. $(1999: 57-58)^{17}$

Sin embargo, el análisis de Schwarz es problemático ya que tiende a poner el acento en la cuestión de la toma de conciencia (es verdad que más en los años setenta que en los noventa) acerca de los auténticos rumbos de cambio que la sociedad brasileńa debería adoptar y, de ese modo, el peso mayor de su diagnóstico todavía recae exclusivamente sobre los intelectuales, a quienes atribuye la responsabilidad social inequívoca de conducir tales transformaciones. Es la misma conexión que nos propone Antonio Candido para pensar la relación entre «Literatura y subdesarrollo» (1972); ${ }^{18}$ pero es incluso también la misma que defendía, en las antípodas, Roland Corbisier, fundador del Instituto Superior de Estudos 
Brasileiros (1955), diputado federal (Ртв) por el extinto estado de Guanabara, preso en 1964, quien, a los ojos de Schwarz, no pasaba de ser un representante de la versión deletérea de la revolución, en función de un denostado populismo. ${ }^{19}$ Esto es así por un motivo muy simple: por tras de todos ellos está Hegel, el hombre para quien el Estado es todo y el individuo nada, es decir, alguien para quien la moral significa tan sólo una forma subordinada de la vida espiritual, o sea, para decirlo con las palabras de Eric Weil, un apologista del Estado prusiano. Contra esa figura, Agamben nos propondría la contrafigura del inoperante, que es justamente un intelectual que no se piensa ni como amo ni como esclavo. Hasta Adorno y Horkheimer, maestros de Candido y Schwarz, supieron admitir, en el prefacio a la primera edición alemana de la Dialéctica del iluminismo, por ejemplo, que ese movimiento debía cuestionarse a sí mismo, si no quería que los hombres fuesen completamente traicionados. Porque no se trataba de conservar el pasado, sino de realizar sus esperanzas. Mientras que, tras la guerra, tras las dictaduras, el pasado continuaba incólume, como destrucción del pasado. Más aún, diríamos. La lectura autoconciente y regulada de Schwarz embute también una defensa del realismo (Lukács) y una consecuente ojeriza antibarroca que, de modo alguno, es privativa del secuestro que Haroldo de Campos le achacara a Candido en su Formación de la Literatura Brasileña. ${ }^{20} \mathrm{Y}$ una de las fuentes es precisamente la evaluación del conflicto social y cómo procesarlo. Veamos este punto con más detalle.

\section{Antagonismo barroco}

Galvano Della Volpe, ex alumno de Rodolfo Mondolfo, profesor de filosofía en la Tucumán de la guerra, y gran defensor del barroco, ${ }^{21}$ mantuvo una polémica, en ámbito marxista, acerca de la noción de contradicción, de la que ya se le podía intuir un desarrollo teórico en su ponencia en el congreso de Filosofía de 1949. ${ }^{22}$ En Lógica como ciencia positiva, publicada un ańo más tarde, Della Volpe partiría de la distinción trazada por Kant sobre las magnitudes negativas, dentro de las cuales distinguía la contradicción lógica, es decir, contradicción entre conceptos, y la oposición real, que es la existente entre los objetos del mundo. El propio Marx ya había definido su tarea como una teoría de los conflictos (Kollisionen) aunque a veces también dijese que su objeto eran las contradicciones (Widersprüche) de la sociedad de su época. Pero en la Critica de la razón pura, en la sección sobre la anfibología de los conceptos de la reflexión, Kant retoma la misma distinción que usara en su crítica a Leibniz. La posición del barroco Della Volpe consistía asimismo en subrayar que el antagonismo no puede ser una contradicción, simplemente porque la contradicción no puede ocurrir entre objetos no-lógicos, argumento que Peter Dews usaría más adelante contra Derrida («Political antagonisms, however, cannot be reduced to logical contradictions» -35-). Pero Della Volpe plantearía además que la filosofía hegeliana podía reducir los antagonismos sociales a contradicciones, sólo porque era una filosofía idealista que reducía la realidad a los conceptos, mientras que una filosofía ma- 
terialista como el marxismo, que afirmaba el carácter extra lógico de lo real, no podía pensar que en el mundo real hubiera contradicciones.

Ernesto Laclau, fuertemente influido por los dellavolpianos, como también uno de los traductores del maestro italiano, Raul Sciarreta, más tarde maestro a su vez de los lacanianos argentinos, supo trabajar con la hipótesis contraria de que los antagonismos sociales no son relaciones objetivas, aunque sí son el límite de toda objetividad; es decir, son el instante en que la sociedad descubre su imposibilidad de constituirse como orden objetivo necesario. Y esa sería una gran línea divisoria entre los partidarios de la conciencia, el realismo y la mímesis y los defensores de la estrategia, el barroco y la aisthesis: o bien decimos que los antagonismos son relaciones objetivas, y en ese caso debemos ir más allá de la conciencia de los agentes, porque si tenemos, pongamos por caso, una relación entre un campesino y un terrateniente, o lo que es lo mismo, si leemos la literatura moderna como tensión entre regionalismo y vanguardia (Ángel Rama), el momento de choque entre ambos no puede ser considerado un momento objetivo (no, al menos, desde el punto de vista del discurso del campesino y ni siquiera del propietario; no, al menos, desde el punto de vista del regionalista y tampoco del vanguardista), sino que esa tensión es sólo un momento objetivo para el punto de vista de un tercer hombre, que ve el antagonismo de una manera que presupone que la conciencia de los dos actores es una mera conciencia deformada, que el antagonismo es de hecho una cosa diferente de lo que viven por sí mismo los participantes de esa relación y que sólo él puede evaluar olímpicamente. Esa es la astucia de la razón en Hegel; y es también la manera en que Marx presenta el proceso histórico como dominado por una lógica que escapa por completo a la conciencia de los agentes sociales. Vale decir, una versión objetivista y reductora. O bien - cabe aquí la otra posibilidad - no hay un tercer hombre. O sea que, además de los que intervienen en la lucha, no hay otro punto de vista, todos estamos implicados en la lucha. Pero, en ese caso, el momento del antagonismo es un momento irreductible, semejante, según el mismo Laclau, o incluso Jorge Alemán, que acompaña su lectura (Alemán:89-III), al concepto de lo real en Lacan, que está presente, pero que no puede ser controlado por ninguna perspectiva simbólica. Es lo que en los años 70 buscaba el grupo Literal y que se constata en los desarrollos teóricos de Libertella o Ludmer, para citar apenas dos de sus protagonistas.

Todo mecanismo de exclusión forma parte pues de un fenómeno más amplio, que es el antagonismo como tal, el cual señala la imposibilidad de subsumirlo a una lógica más profunda, que lo licuaría y lo presentaría como algo diferente de lo que pretende ser. Como ese hecho sólo existe desde la perspectiva de los agentes finitos, que sobre él van a tener discursos limitados, desde ese punto de vista, la contingencia va a estar presente siempre en todos los discursos. En el primer caso, la voluntad de potencia se transformó en simple voluntad de dominio; en el segundo, se tradujo como voluntad de chance (Bataille), es decir, contingente, inmanente, aleatoria. Si la primera perspectiva tiende a afianzar el orden simbólico, la segunda bordea la khôra semiótica, como preveía Kristeva. La primera se 
pauta por la producción y asienta en un intercambio de valores de trueque, en la línea estudiada por Bourdieu. La segunda, claramente profanatoria, trabaja, en cambio, con un valor de uso de lo imposible. Laclau extrae de este giro varias consecuencias y argumenta, en primer lugar, que la perspectiva de los agentes sociales está siempre amenazada por la forma fenomenal de esta contingencia, que es la presencia amenazadora de ese otro radicalmente heterogéneo, que no puede ser reducido al mismo nivel de representación en el que se construye la identidad del primer agente. Esto se contrapone no sólo a la perspectiva ideológica de Schwarz, sino también a la perspectiva dialógica de Habermas, ${ }^{23}$ según las cuales habría unos procedimientos (marxistas en Schwarz; social-demócratas en Habermas), gracias a los que, por medio de un intercambio racional y conciente, se llegaría a una perspectiva única. Laclau, Lacan, nos dirían, en cambio, que hay perspectivas que no pueden sintetizarse, pero que, si una perspectiva triunfa sobre otra, es porque los mecanismos son simplemente hegemónicos.

Cuando una perspectiva comienza a sumar elementos de otras perspectivas antagónicas, de modo que a cierto punto se transforma en un punto de vista general, estamos ante lo que Gramsci llamaba hegemonía y la historia (entre otras, la de la literatura) no sería sino una sucesión discontinua de formaciones hegemónicas. ${ }^{24} \mathrm{La}$ formación hegemónica, como formación contingente y limitada, es el horizonte en que es posible construir lo social en determinado período. ${ }^{25}$ Como relatos que son, tales formaciones hegemónicas pueden constituir constelaciones y nudos de sentido. En historia literaria, el mejor ejemplo que conozco es la historia de la literatura francesa de Denis Hollier, ${ }^{26}$ o incluso En 1926 de Hans-Ulrich Gumbrecht (2004), potencializado en su reciente After 1945. Latency as Origin of the Present (2013).

Para volver a Della Volpe, recordemos que, poco después del congreso de Mendoza, publica su ensayo pionero sobre el verosímil fílmico (1952), donde desarrolla la teoría de una estética vinculada a las sensaciones, en que el verismo filmico, como el de Visconti en Senso (1954), que es, al mismo tiempo, cine y pintura, literatura y política, se caracteriza por reivindicar la especificidad del arte en oposición a sus aspectos cósmicos, una vez que el arte es un problema intelectual finito, empírico, temporal e histórico y lo estético se equipara así al conocimiento, adquiriendo el carácter existencial del juicio, lo cual lo llevaría a definir la poesía como tipicidad característica polisema, frente a la ciencia o prosa del mundo, que es una tipicidad característica unívoca. De allí deriva asimismo su consistente censura al realismo crítico cuando lee las alucinantes alegorías de Kafka, satirizando angustias existenciales, religiosas o metafísicas, donde Lukács, según Della Volpe, corre el peligro de profunda incoherencia, ya que se esfuerza por analizarlas (a diferencia de lo que hace con Proust y Joyce, a quienes simplemente descarta), pero usa para ellas el término «alegoría», aunque en sentido peyorativo, y niega que Kafka llegue a elevar el particular individual a la particularidad de lo típico, mientras, por otro lado, admite que en Kafka la concepción de los detalles particulares es selectiva, de tal modo que subraya eficazmente lo 
esencial. ¿No sería posible aproximar este antagonismo de Proust, Joyce o Kafka, al drama de la Muerte (del esteta wildeano) en Venecia, o a la confesión del egoísmo del artista romántico-decadente en Tonio Kröger, o a la tragedia del final de la gran familia hanseática en los Buddenbrooks, del «siempre inmanente» (según Lukács) Thomas Mann? — se pregunta Della Volpe (1972:292)— quien no desprecia el amasijo de serpientes históricas, completamente warburguiano, que supone un antagonismo estético-social, en que las temporalidades evolutivas, histórico-culturales, se yuxtaponen y confrontan imitando la cabeza de Medusa. La posterior evolución cinematográfica de Visconti, filmando con senso las caídas (de la burguesía alemana e italiana, o del esteticismo de von Aschenbach o del rey Ludwig) le daría la razón a Della Volpe. Pues en el último capítulo de su Crítica del gusto, vuelve el filósofo al Laocoonte (1766) de Lessíng, para resituarlo en su presente (1960), contraponiéndolo a la comparación horaciana de la poesía-pintura, lo cual invita a desplazar nuestra atención de las cosas representadas por poetas y pintores para los medios expresivos correspondientes, con lo que Della Volpe concluye que la poesía no expresa, ni detalla menos perfectamente con sus medios expresivo-semánticos (la palabra) que la pintura con líneas y colores o la escultura con volúmenes. La gratitud que se le debe a Lessing, según Della Volpe, sólo puede medirla quien se esfuerce por no recaer en aquella indistinción o confusión de las artes causada por el concepto metafisico-idealista del arte como imaginación creadora, o la confusión romántica entre arte y naturaleza, que le recuerda al crítico lo que narra el gran viajero James Cook a propósito de un jefe neozelandés que, entrado en la cabina del capitán, no conseguía, ni por un momento, fijar su atención en nada, por lo cual las obras de arte se le mostraban a la misma luz que las cosas naturales, confundidas las frutas pintadas con las reales. En esa situación, muy recurrente por lo demás en las ficciones de César Aira, a quien podríamos definir como un barroco conceptual, el metartístico y el salvaje, por principio y hábito mental el primero y por falta de entrenamiento estético el segundo, comparten la misma ojeriza al análisis o simplemente a la distinción del antagonismo existente entre fuerza y pensamiento (217-219). No sería descabellado, para no salir de la literatura argentina, inscribir en esa línea al Borges de Inquisiciones, al ensayismo de Murena o el de Horacio González, a la poesía de Tamara Kamenszain o Martín Gambarotta. Cuanto más los textos pertenecen a una literatura menor, en el sentido que Deleuze le daba a la expresión, más identidades se agregan a esos textos y mayor apertura nos proponen. Por lo tanto, toda literatura menor es una gran literatura. ${ }^{27}$

Walter Benjamin abría su ensayo sobre la filosofía futura argumentando que la tarea central de la filosofía venidera es la de extraer y hacer patentes las más profundas nociones de contemporaneidad y los presentimientos del gran futuro que sea capaz de crear, con relación al sistema kantiano. Podríamos reescribirlo y decir que la tarea central de la filosofía venidera es la de extraer y hacer patentes las más profundas nociones de contemporaneidad y los presentimientos del gran futuro que sea capaz de crear, con relación al sistema hegeliano. Y completar el 
juicio agregando, además, como Benjamin, que cuanto más imprevisible y audaz se nos anuncie el despliegue de la filosofía venidera, tanto más profundamente deberá producir certeza, certeza cuyo criterio es la unidad sistemática o, simplemente, la verdad.

Si la hegemonía, por lo tanto, es una formación contingente y parcial, que construye lo social (el sentido, los valores, las instituciones) de un momento dado, es ilustrativo ver cómo se puede concebir la investigación literaria en ese marco. ¿Qué verdad está allí en juego? Lo que se debate y dirime entonces es la potencialidad, en una sociedad democrática, de remar contra la especialización y, no obstante, a favor de la construcción de un espacio común de referentes compartidos, reuniendo una diversidad de saberes, en una unidad metodológica consistente, de tal suerte que los contenidos de la formación no sean unilateralmente dictados por las exigencias de la economía, sino que puedan ser definidos por las relaciones que estos saberes mantienen entre sí y por el modo en que se cruzan en el interior de una cultura que, aunque letrada, esté cada vez menos alejada del espíritu de su época. Si el Mercosur va a ser algo más que mera unidad económica, una auténtica contribución a la construcción del espacio cultural compartido pasa por repensar qué hacer con la Universidad y su práctica de investigación. Les propongo, por tanto, un Laocoonte, 2013.

Tomemos, para ello, el caso de un maestro como Foucault. Mientras la perspectiva fenomenológica era totalmente hegemónica en Francia, el concepto foucaultiano de investigación se limitaba a ser tan sólo oposicional.

Il y a là sans doute un trait qui peut caractériser la situation de toute recherche par rapport à la science constituée: elle se fait toujours contre un enseignement, aux dépens d'une objectivité reconnue, elle mord sur un savoir beaucoup plus qu'elle ne le complète et ne l'achemine vers sa fin; par sa naissance au moins, elle appartient toujours, peu ou prou, aux marges de l 'hérésie de la science; toute l'histoire de la biologie a manifesté ce fait et l'a exalté jusqu'aux formes religieuses de l'anathème. (...) La recherche apparaît bien plutôt ici comme une conduite de détour par laquelle la connaissance constituée se trouve court-circuitée et invalidée au nom d'une réduction de la science à son objet par un décalage qui fait de la science non plus l'horizon problématique de la recherche, mais l'objet polémique de son investigation. (I944:192)

En ese punto, Michel Foucault no está muy distante de Paul Valéry, quien por entonces argumentaba que "c' est une faiblesse que de se dépenser contre un adversaire au lieu de rérservar et concentrer ses forces pour soi... et de préference contre soi» (383). Como nos decía Laclau, la perspectiva de los contendores sociales está siempre amenazada por la forma fenomenal de esa contingencia, vivida como la presencia amenazadora de un Otro radicalmente heterogéneo, imposible de ser reducido al mismo nivel de representación con que se construye la identidad del primer actor. Pero treinta ańos más tarde, en 1984, cuando Foucault investiga El coraje de la verdad y discrimina entre zêtêsis, exetasis y epimeleia, argumentando que zêtêsis es la investigación socrática; exetasis es el examen del alma y epimeleia, 
el cuidado de sí, al que creía debiéramos volver, como antídoto al neoliberalismo emergente, entonces Foucault se muestra mucho más cauto sobre las posibilidades contra-institucionales de la investigación y propone, en cambio, que

Quizá será preciso hacer algún día la larga historia de la polémica como figura parasitaria de la discusión y obstáculo en la búsqueda de la verdad. Muy esquemáticamente, me parece que en ello se podría reconocer hoy la presencia de tres modelos: modelo religioso, modelo judicial y modelo político. Del mismo modo que en la heresiología, la polémica se propone como tarea determinar el punto de dogma intangible, el principio fundamental y necesario que el adversario ha descuidado, ignorado o transgredido; y en esta negligencia, denuncia la falta moral; en la raíz del error, descubre la pasión, el deseo, el interés, toda una serie de debilidades y vinculaciones inconfesables que la constituyen en culpabilidad. Como en la práctica judicial, la polémica no abre la posibilidad de una discusión en condiciones de igualdad; instruye un proceso. No se ocupa de un interlocutor, trata un sospechoso, reúne las pruebas de su culpabilidad y, designando la infracción que ha cometido, pronuncia el veredicto y dicta condena. En todo caso, no estamos en el orden de una indagación llevada en común; el polemista dice la verdad en la forma de un juicio y según la autoridad que le es conferida a sí mismo.

Pero hoy en día el modelo político es el más poderoso. La polémica define alianzas, recluta partidarios, coliga intereses u opiniones, representa un partido; constituye al otro en un enemigo portador de intereses opuestos contra el que hay que luchar hasta el momento en el que, vencido, no le cabrá sino someterse o desaparecer.

Sin duda, en la polémica la reactivación de estas prácticas políticas, judiciales o religiosas no es otra cosa que teatro. Se gesticula: anatemas, excomuniones, condenas, batallas, victorias y derrotas no son, después de todo, sino maneras de decir. Y sin embargo son también, en el orden del discurso, maneras de hacer que no carecen de consecuencias. (1999:354)

\section{Pragmatismo}

Prefiero retener el último juicio: como las polémicas son también, en el orden del discurso, maneras de hacer, no carecen de consecuencias y es a ellas que quisiera abocarme. ¿Cuáles son los modos de hacer investigación en el campo de la literatura que se nos presentan en este momento? Diría que la negatividad y la no evidencia de la literatura, su radical y absoluta inmanencia, ${ }^{28}$ se manifiestan hoy día por medio de la singularidad del surgimiento autónomo de una obra, que impide su identidad con la totalidad del concepto de «literatura», lo cual genera a su vez un movimiento paradójico: para poder constituirse como barrera de negatividad ante el concepto, cada texto tiene que ir más allá del arte, tiene que trascender su condición de pertenencia al concepto y a la misma institución literaria, para poder por fin apuntar a un horizonte bioestético, desbordado hacia el mundo circundante. Eso siempre implica un afuera, un más allá de la literatura, que, sin embargo, no anula su momento de autonomía, sino que lo requiere como impugnación de su no-identidad mimética. Ya lo decía el citado Della Volpe: se trata de verla como una 
autonomía técnica (semántica, precisamente), y no como autonomía metafísica o de una hipóstasis gnoseológica, la hipóstasis-Arte, ya lo sea de lo ideal o universal (...), a la manera aristotélica y racionalista-abstracta, ya lo sea de lo particular como entusiasmo o raptus, o sentimiento desinteresado, intuición o fantasía, etc. (...), a la manera platónica y románticoidealista. (1966:174-175)

Hay, por lo tanto, una heteronomía del arte (subordinada a la idea, a la manera), y una autonomía del artificio (el ornato: lo barroco). La ley y el crimen (Rabatè). La literatura sería pues heteroautónoma. En ese sentido, las operaciones de lectura que propondría, al perseguir ciertas matrices singular-concretas, no generalizables ni al concepto ni a la institución literaria, nos presentan un desborde de la obra sobre el mundo de lo cultural, lo antropológico y hasta incluso lo etnográfico. Más que el deslinde perseguido por Alfonso Reyes en 1944, nuestra época, en última instancia, busca un desborde sobre el campo de lo político. Persigue una forma de extrańamiento que restituya al sujeto a una intimidad de vida que se le ha vuelto extraña, éxtima, para sí mismo, proscrito y desgarrado de sí. Con la noción de deslimitación, la subjetividad que se rebasa a sí propia no queda destronada o, mejor aún, comprende en la piel el sentido de la expresión heitomasia tou thronou, el trono está vacío. Queda así desposeída de su antiguo poder, en pos de un destino para su Ser, aunque restituida a la espontaneidad de sus pulsiones más vedadas.

Uno de los críticos más influyentes en el escenario contemporáneo, Georges Didi-Huberman, ${ }^{29}$ se pregunta, por ejemplo, qué clase de objeto encontraba Aby Warburg en sus experiencias inquietantes, muy anteriores a la categoría de lo siniestro, que Freud sólo acuñaría en I919. Warburg vio, gracias a esa ciencia sin nombre, un objeto triple que, al mismo tiempo, era imagen, pero también acto (corporal, social) e incluso símbolo (psíquico, cultural), es decir, una sopa de anguilas teórica, tal como una cabeza de Medusa vagando en lo eterno, un amasijo de serpientes, en que las temporalidades evolutivas de la cultura se cruzan y entran en conflicto, ya que los opuestos se encabalgan en constelaciones y las diacronías lineales se vuelven sincronías conflictivas. La supervivencia que desarmoniza y desestructura la apariencia no es por lo tanto un mero rezago cultural, una rémora del pasado, como argumentaría Schwarz: es un fantasma, la figura vampírica del muerto-vivo, cuya sombra acecha dentro mismo de lo familiar y confortable.

\section{Espectros}

En El sitio de la mirada, Eduardo Grüner nos recuerda que Warburg traducía la consigna freudiana Wo Es war, soll Ich werden (donde era el Ello, que advenga el Yo) por la frase latina Per monstra ad astra. Más aún, en su libro Per monstra ad sphaeram, el mismo Warburg analiza una imagen de la Fortuna cuyos cabellos son siempre agarrados y empujados violentamente por detrás, imagen que se conoce con la tan enigmática como ambigua frase Velis, nolisve. ${ }^{30}$ Diríamos, entonces, que, en efecto, el «retorno» contemporáneo del concepto de sobrevivencia, 
más que a completar una ausencia, viene a producir el vacío allí mismo donde la imagen parecía plena y auto-suficiente. Donde hay falsa transparencia, haya densa ambigüedad, velis, nolisve. En consecuencia, más que de una dialéctica de lo visible/invisible, hegemónica en el período fenomenológico, podríamos pensar que la contemporánea survivencia, para decirlo con Macedonio, nos permite la intermitencia icnológica, una suerte de centelleo inconstante de la imagen, de innegable sentido político (baste pensar en las luciérnagas de Pasolini —Didi-Huberman-) en que el lector discontinuo se depara con el no existente caballero.

En el tantas veces referido congreso de Filosofía de 1949, Karl Löwith decía que no habría búsqueda alguna por el significado de la historia, si éste estuviera claramente manifiesto en los acontecimientos. Es justamente porque no hay significado para los acontecimientos mismos, que surge la pregunta por el sentido e inversamente, es sólo dentro del horizonte pre-establecido de un último significado, no importa lo escondido que se encuentre, que la historia corriente parece carecer de sentido. Este horizonte ha sido establecido por la misma historia, pues es el pensamiento hebreo y cristiano el que ha dado existencia a esa extraordinaria pregunta. Cuestionarse seriamente pues por el último significado de la historia nos deja sin aliento. Nos transporta a un vacío que sólo la esperanza y la fe pueden colmar. El futuro es el «verdadero» foco de la historia, suponiendo que la verdad resida en los fundamentos religiosos del Occidente cristiano, cuya conciencia histórica está determinada por una motivación escatológica, desde las Escrituras a Marx, desde San Agustín a Hegel. Daría la impresión, concluía Löwith, que las dos grandes concepciones de la antigüedad y del mundo cristiano, movimiento cíclico y dirección escatológica, hubieran agotado todos los intentos básicos conducentes a la comprensión de la historia, anticipando así los argumentos de su obra definitiva, Historia del mundo y salvación (I700-1709).

Años más tarde, en Homo sacer, Agamben destacaría que Karl Löwith fue el primero en definir la "politicización de la vida» y, en consecuencia, la curiosa y problemática contigüidad entre democracia y totalitarismo. Pero en El tiempo que resta, el mismo Agamben le recrimina a Löwith confundir mesianismo y escatología, el tiempo del fin y el fin del tiempo, siendo que esta última alternativa es todavía su posición ético-política más emblemática: la búsqueda no ya de potestas sino de auctoritas, no sólo de legalidad, sino de legitimidad. ${ }^{31}$ Jacques Derrida, a su vez, nos habló de una escena política atravesada por los espectros de Marx, que transformarían todo saber poshumano en una hantología, un saber de los espectros (Meillassoux). Recientemente, Fabián Ludueña argumentaba que si esa hantología no es, como puede leerse en Derrida, tan sólo la reversión de la metafísica como ontología, sino un fenómeno concomitante a la estructura más íntima de la misma ontología, el espectro ya no será una simple forclusión invertida, ni una carencia sensible. Al contrario, podrá aspirar a mostrarse tan libre de la «realidad» como de la «irrealidad», sin necesidad de ninguna conciencia trascendental, ni de ningún mundo humanamente concebido. En ese sentido, sin embargo, se impondría cierta distinción. La teología cristiana y la desconstrucción derridiana se baten en un mismo terreno por la definición de su objeto: para la teología, el 
Espíritu es la forma suprema del aparecer mediador, según el dispositivo de la Trinidad, mientras que, para la desconstrucción, en cambio, no hay saber sobre el Espíritu que no sea una temporalidad impura del espectro que desmonta y desmiente la pureza del Espíritu. El desafío, según Ludueña, consiste en pensar la zona metafísica aludida por la espectralidad bajo un modo nuevo, que supere las aporías de la teología dogmática. Y el único modo de lograr tal propósito, a su juicio, es volviendo posible un saber positivo sobre el espectro, que pueda disputarle verdaderamente a la teología el conocimiento del mundo espectral.

Una tarea de esta índole implica, con todo, dar un paso a partir de la deconstrucción pero, también, más allá de ella hacia una ciencia de lo espectral en cuanto tópos in-sistente por fuera de toda fenomenología de la vivencia, por fuera de todo trascendentalismo entendido como las condiciones del aparecer y, finalmente, por fuera de toda pneumatología como ciencia de la potestas spiritualis. Un proyecto semejante conlleva también la necesidad de abrir las puertas a una post-metafísica de la espectralidad entendida no sólo como apertura hacia una nueva política sino, primordialmente, como ciencia de una nueva forma de pensar la política. (Ludueña Romandini:I47)

Una suerte de neo-filología (no del genos sino de la arché) es una de las formas de ensayar esa hantología propuesta por Ludueña en el campo de la literatura. Siraj Ahmed, en su reciente ensayo «Notes from Babel: A Colonial History of Comparative Literature», nos dice a ese respecto:

The study of world literature would be more attuned to its own genealogy, if it acknowledged how profoundly both its materials and its methods are a colonial legacy. Colonial philology disembedded native literatures from their traditions so that it could dissever native subjects from their forms of life. It initiated a transformation so massive that no tradition now remains untouched. Historicist humanism authorized this transformation. It argued that philologically reconstructed texts contain the truth of tradition more authentically than people themselves do. It became hegemonic — the basis of both critical method and colonial domination - because it enabled modern institutions to impose analytic and bureaucratic order on multilingual terrains. $(322)^{32}$

La tarea de una archifilología no asume el método histórico de forma acrítica, sino que se cuestiona acerca de las políticas del tiempo e incisivamente se pregunta si alguna de ellas no ha sido cómplice quizás en la destrucción de valores culturales. El objeto de lo que podríamos llamar una archifilología no es pues la representación de algo ya dado, sino la idea o el gesto crítico que nos permitan barajar y dar de nuevo, porque nunca se repite lo pasado, sino que sólo se accede a aquello que de ese pasado camina hacia el futuro. No se afirma ni la unidad de objeto disciplinario, ni su inmovilización temporal: espacios y tiempos heterogéneos no cesan de cruzarse, confrontarse, encabalgarse o amalgamarse en una lectura archifilológica. Prestar atención a esas constelaciones de elementos, 
configuraciones de sentido o encabalgamientos de valores implica reconocer que dichas constelaciones, configuraciones y encabalgamientos están regidos por el con, por la articulación, más que por una esencia autónoma, pretendidamente común o compartida.

Si la modernidad trabajó con la hipótesis de pueblos primitivos que se identificaban con animales y plantas sagradas o que, a partir de sus cualidades, se adjudicaban nombres a sí mismos, ${ }^{33}$ así como había locos que también se reconocían en los objetos de sus percepciones; si hubo enfermos que no se atribuyeron las sensaciones de sus cuerpos a sí mismos, sino que se las proyectaron a otros seres, así como hubo videntes que se apropiaron de las percepciones de otros, la experiencia estética que a partir de ellos fue elaborando la modernidad acabó por brindarnos un tipo de conciencia afectada, atravesada por un afecto, el afecto del lenguaje por el lenguaje, por eso que una lectura que busca el origen, como la archifilología, sólo puede buscar la meta, en la medida en que cada objeto tiende a la actualización de su origen y, siendo afecto del lenguaje por sí en cuanto otro, la archifilología no es sino una archi-filo-fília. ${ }^{34}$

Such an archaeology would trace not only the colonial arrangement of knowledge that shaped historical method —and secular criticism as well— but also the precolonial language practices that existed outside this arrangement. An archaeological project of this kind is, as Agamben has emphasized, philology turned against itself —or "the destruction of destruction"». This project must be part of the comparative literature to come, whose task involves unearthing the approaches to language the new philology buried in its colonial past. (Ahmed:326) ${ }^{35}$

Notas

${ }^{1}$ Este trabajo es fruto de un seminario dictado en la Universidad Nacional de Cuyo en noviembre de 2013.

2 Ver Survey de Gerhard Richter, 20or; Susan Laxton, 2012.

${ }^{3}$ Y explica: «Si algo del americanismo primitivo llegó a infiltrarse en esta poesía (lo cual es muy dudoso), sólo en este sentido podrán tener cabida tales elementos bárbaros y exóticos en un cuadro de la literatura hispanoamericana, la cual, por lo demás, ha seguido en todo las vicisitudes de la general literatura española, participando del clasicismo italiano del siglo xvı, del culteranismo del XviI, de la reacción neoclásica del xviII, del romanticismo del presente y de las influencias de la novísima literatura extranjera, especialmente de la francesa y de la inglesa. Esto no excluye gran originalidad, más bien que en opacas, incoherentes y misteriosas tradiciones de

gentes bárbaras o degeneradas (sic), que para los mismos americanos de hoy resultan mucho más extrañas, menos familiares y menos interesantes que las de los asirios, los persas o los egipcios; ha de buscarse en la contemplación de las maravillas de un mundo nuevo, en los elementos propios del paisaje, en la modificación de la raza por el medio ambiente, y en la enérgica vida que engendraron, primero el esfuerzo de la colonización y de la conquista, luego la guerra de separación, y, finalmente, las discordias civiles. Por eso lo más original de la poesía americana es, en primer lugar, la poesía descriptiva, y en segundo lugar, la poesía política. Todos los demás géneros cultivados en Europa están representados allí por ensayos más o menos felices, $\mathrm{y}$ aun por obras de mucho precio, que son bastante más que tentativas; pero hay en todo esto mucha labor de imitación ingeniosa y hábil, 
muchos versos que lo mismo podrían ser firmados en Madrid o en París que Buenos Aires, en México o en Caracas. Hay gran número de autores americanos, aun de los más dignos de estimación, en quienes el que a cada paso le afectan, es cosa falsa y postiza. Tal cualidad, o es innata o no se adquiere con estudio: Bello y Heredia la encontraron dentro de una escuela académica, y todavía no es seguro que hayan llegado a ser tan americanos los muchos poetas que de propósito deliberado han querido pasar por aztecas, guaraníes y araucanos».

${ }^{4}$ Ver Foster: Recodings, Art, Spectacle and Cultural Politics, 1986; Compulsive Beauty, I993; El retorno de lo real, I996; Dioses prostéticos, 2008; "The "Primitive Unconscious" of Modern Art», I985; "Amour Fou», I991; "Convulsive Identity», I99I; "Posmodernism in Parallax», I993. Además, Krauss, Rosalind: La originalidad de la vanguardia y otros mitos modernos, 1985; El inconsciente óptico, 1993; Lo fotográfico. Por una teoría de los desplazamientos, I990; "Corpus Delicti», I985; "Michel, Bataille et Moi», I994; Krauss, Rosalind y Jane Livingstone: L'Amour Fou: Photography and Surrealism, 1985; Krauss, Rosalind e YveAlain Bois: L'informe, mode d'emploi, 1996.

5 Ver Scramim, "A exceção e o excesso», 2005.

6 Basten dos ejemplos rigurosamente contemporáneos y no necesariamente radicales, Krauss: "The Angel of History», donde la autora analiza aspectos de la obra de Marcel Broodthaers; o Mitchell, «Image, Space, Revolution: The Arts of Occupation», donde el autor de Teoria de la Imagen y Cloning Terror: The War of Images, g/II to the Present, analiza ciertas imágenes de la ocupación en Wall Street y en El Cairo.

7 Un texto pionero (años 40) en esa línea: Romero, José Luis «Los contactos de cultura: bases para una morfología» en La vida histórica, 1988.

8 «Verso la fine del Medioevo, nei paesi dell’ Europa continentale, principi ed eruditi raccoglievano gli oggetti più disparati in una Wunderkammer che conteneva promiscuamente pietre di forma insolita e monete, animali imbalsamati e libri manoscritti, uova di struzzo e corna di unicorno. Quando si cominciarono a collezionare oggetti d' arte, in queste camere delle meraviglie statue e pitture si affiancarono alle curiosità e agli esemplari di storia naturale; ma, almeno nei paesi germanici, le collezioni d' arte dei principi conservarono fino a tardi l'impronta della loro discendenza dalla Wunderkammer medioevale» (Agamben 1970:46).

9 Romagosa dice que «las poesías brasileras y los sonetos en francés del cubano Heredia los he publicado originales, porque, en primer lugar, no hay traducciones fieles y artísticas, $y$, en segundo lugar, porque el portugués es un idioma tan diáfano, que es fácilmente comprensible para la generalidad, y el francés nos es familiar a todos los americanos» (XI).

10 Ver también Cadava y Cortes Roca, 2005 y 2006.

${ }^{11}$ Ver Belting.

12 Ver Collins.

13 Ver Caillois; y también Monahan.

14 Ver también Déotte.

15 Antes de ser publicado como capítulo inicial de $A o$ vencedor, as batatas, tenemos también, del mismo autor, «Dépendance nationale, déplacement d’idéologies, littérature: sur la culture brésilienne au XIxème siècle», 1972.

16 Para un análisis spinozista del conflicto, ver Chaui.

17 Me detuve en ello en Antelo 2003. El mismo debate propuso recientemente, en Estados Unidos, una estética recesiva. Interrogados por Yve-Alain Bois, Hal Foster y David Joselit, el designer Andrew Witt, director de investigaciones de Gehry Technologies y el artista Nathan Crompton respondieron que «faced with ever-increasing cuts to funding, combined with the exorbitant costs of exhibiting, art museums are increasingly driven to find funding, and art itself, elsewhere. We are caught in the era of ready-made shows where art is pulled off the shelves of philanthropists or any one of the transnational banks-JP Morgan Chase, uBs, Deutsche Bank. In other words, the art institutions' financial instability becomes a pretext for collusion with a colony of destabilizing financial powers. Rather than being recognized as the agent whose daily prerogative is to flatten the world and take greatness out of circulation, "great" wealth becomes the benevolent facilitator for the circulation of "great" works. A few rarely circulated masterpieces become cultural bargaining chips in a philandering that amounts to nothing more than the thoughtful legitimation of thoughtless consumption. In an environment where institutions such as Bank of Ameri- 
ca annually produce a variety of ready-made shows for "temporary lending" (mirroring the chrematistics of it $s$ everyday lending practices), it might appear liberating, almost archaically so, that curators may still exercise a bit of autonomy. (...) Just as the "mixed economy" is the preferred means for a society dominated so thoroughly by capital, the neoliberal art museum is sustained by its very unsustainability. For us, it is not a question of finding an alternative model of funding latent somewhere within the current neoliberal one, or even making the presentation of art more "economical" or "sustainable" within late capitalism. On the contrary, it is a matter of discovering an inoperative model vis-à-vis the neoliberal art museum».

18 Ver Candido, I99I; y del mismo autor Ensayos y comentarios, I995. Sobre el autor, ver Antelo, 2001.

19 «A semana de arte moderna, antecipando-se de certo modo à revolução, foi talvez um sintoma dessa necessidade de tomar consciência do novo Brasil que estava nascendo. Não ultrapassou, porém, o plano literário e a sua mensagem se reduziu a um vago pressentimento de que era preciso redescobrir a terra afogada num mar de palavras, de retórica no mau sentido, de demagogia. Faltou-lhe, no entanto, informação e perspectiva filosófica para realizar esse empreendimento, essa tarefa urgente de recuperação de um país perdido. As revoluçóes posteriores, que traduziram o nosso desajustamento fundamental, o nosso orgânico mal-estar, a ditadura e a guerra, deveriam traumatizar a inteligência brasileira, confinando-a quase toda no particularismo profissional e no trabalho especializado. Estamos ainda convalescendo dessa fuga para a vida privada que é um dos nossos males mais graves, um dos maiores obstáculos a qualquer trabalho de equipe, indispensável a qualquer empreendimento político serio.

Porque o problema brasileiro é, em primeiro lugar, um problema de consciência. Náo temos errado apenas por malícia, egoísmo ou falta de probabilidade, mas também por ignorarmos o terreno no qual estamos pisando como exploradores que, privados do mapa da região, se perdessem no meio de uma selva espessa. A lição de Sócrates, resumida no lema da sua filosofia, não se dirige apenas aos indivíduos mas às sociedades. Nenhu- ma reforma, nenhuma transformação moral é possível sem o prévio conhecimento da realidade que se pretende modificar. Qualquer plano de salvação pública, qualquer programa de reforma política implica necessariamente essa tomada de consciência, essa compreensão e definiçãa do país que se deseja reformar. Nada mais fácil do que inventar no silêncio de um gabinete um programa partidário ou redigir uma nova constituição. Mais difícil e mais árduo é o trabalho de descoberta e caracterização da realidade, a pesquisa de dados e elementos de informação que nos permitem fazer uma idéia junta da situação em que nos encontramos. Temos revelado até hoje uma invencível repugnância por qualquer esforço dessa natureza, transferindo-o sempre para os poderes públicos que o realizam de maneira parcial e insuficiente. De outro modo, não sairemos, porém, da ilusão demagógica que imagina tudo poder solucionar com discursos e palavras, e do empirismo oportunista que só vê os problemas menores e procura atender a eles na medida em que se vão apresentando, e não venceremos essa alternativa que nos condena ou a falar apenas, permanecendo imóveis e estéreis no plano da ação, ou a agir de maneira intermitente e frenética, como se a nossa letargia fosse de ver em quando sacudida por acessos espasmódicos de cuja crispação ainda saímos mais desalentados e gastos» (Corbisier:4 y I4).

20 Ver también Ávila; y «Mário e o barroco» de Avancini.

21 Ver Della Volpe, 1972.

22 En «Sulla genesi aristotélica della contraddizione», Della Volpe argumentaba que «il motore di tutta la "confutazione", cioé il criterio unificante ambo le argomentazioni l'ontologica e la gnoseologica, é il concetto di materia in quanto concetto di una unitá numérica o discreta per eccellenza (radicalmente diversa dall'unitá "specifica” o fórmale): congiuntovi, s’intende, quello di attualita, da esso strettamente dipendente in quanto é concetto di un'attualitá divaricante i contrari. Onde, come la confutazione ontologica fa perno sulla "indivisibilitá numérica" dell'individuo o specie materiata, per la giustificazione del fatto che l'individuo, la sostanza prima, riceve i contrari restando idéntico e numéricamente uno, e pero si attua mediante un solo contrario, cosi la confutazione gnoseologica fa perno sulla unitá numéri- 
ca, o unidla o singolaritá della qualitá materiale sentita, per giustificare quella immutabilitá (nel contrario) che sottrae essa qualitá all'indeterminato e la fa atluale e vera». (Della Volpe 1949:1942).

${ }^{23}$ En su capítulo sobre Foucault de El discurso de la modernidad, por ejemplo, Habermas cree, no sin euforia, que el amortiguamiento o incluso la destrucción de las relaciones dialógicas convierte a los sujetos vueltos sobre sí mismos en meros objetos los unos de los otros y tan sólo en eso, objetos, con lo cual la biopolítica foucaultiana se vuelve un tema de reificación y alienación marxista convencional.

${ }^{24}$ Un gramsciano como Thimoty Brennnan así describe la naturalizada hegemonía neoliberal: «Capitalism, exploitation, and Marxism are all freely and even militantly discussed, but never without carefully disavowing actual revolutionary movements, allegorically summoning a lexicon that suggests the untranscendable good of liberal democracy, and rejecting any actual organizational expression of resistance. To that degree, the selective tradition of theory is not just coincidentally reminiscent of, or ironically echoing, the brand of freedom in mainstream discourse but of a piece with it in a dissembled, self-alienated, form. Placed in an impossible position of being beyond opposition -whose very function, in fact, is to be impossible - critics can only critique if it is critique itself that is ultimately being interrogated; as a result, they can only speak what they disavow, and can only say what they do not say». (Brennan:296).

${ }^{25}$ Ver Laclau, I996; 2000; 2005; 2008; $201 \mathrm{I}$.

${ }^{26}$ Ver Hollier, 1993. Hay una primera edición en inglés: A New History of French Literature. Cambridge, Harvard, 1989. Del mismo autor, El Colegio de Sociología (1937-1939), 1982; Against Architecture: The Writings of Georges Bataille (1979), I993; “Mimesis and Castration, I937», I984; «Bataille's Tomb: a Hallowen Story», 1985; «On Equivocation (Between Literature and Politics)», 1990; «Surrealist Precipitates», 1994; «Formless: A User's Guide», 1996. Fredric Jameson discute la cuestión de la historia en "New Literary History after the End of the New».

${ }^{27}$ Claire Colebrook cita el caso del poeta aborigen australiano Mudrooroo (1938- ) que «includes all sorts of images in his poetry - other black cultures, such as the reggae of Bob Marley, and "contaminating" images from Western capitalism. His work is Aboriginal, not by being a pure representation of some origin, but by creating a specific territory in which being Aboriginal is presented as a process of becoming and negotiation, incorporating and transforming images from without through its own mode of work. Such a literature would become majoritarian when its past examples are read as signs of some underlying essence: if arts councils refused funding to works for not being sufficiently Aboriginal, or if criticism discerned an underlying essence of Aboriginal literature» (II8). Por lo tanto, la cuestión central es una vez más la del retorno de lo eterno y la voluntad de contingencia, que desvincula un texto de su contexto de referencia, espacial o temporal. «A text does not have a context which would limit how it might be read or what it could do. A text, if it is really literary, transfor$m s$ its context, transforms the very context of literature and expresses the power of difference that will open up new contexts. Difference is therefore not a power within time; it is the power of time itself - eternal or untimely. And the only thing that does not change through time, the only eternal, is difference and time itself: always different» (I22). Para una crítica del concepto de contexto en la ideología humanista, ver, de la misma autora, «The Context of Humanism».

${ }^{28}$ Dice Didi-Huberman en una entrevista: «Pour essayer de préciser ma pensée - mais aussi pour rebondir sur votre référence à Deleuze, qui m'importe plus que jamais—, je dirai que les notions par vous évoquées (incarnat, empreinte, informe) tentent de situer l'image dans un contexte théorique que nous devons en grande part à Deleuze : il s'agit de l' immanence, analysée d'abord dans Spinoza et le problème de l'expression, mais qui donne aussi le thème du dernier texte publié de Deleuze (par ailleurs fort bien commenté par Giorgio Agamben) en 1995. Entre le modèle idéal et la copie matérielle, nous pouvons toujours, en manipulant Aristo te avec Platon (comme nous le faisons depuis des siècles), spéculer sur les différences entre cause matérielle et cause formelle, par exemple. L'analyse deleuzienne, elle, nous aide à penser désormais en termes de cause immanente. Non par hasard, la notion d'immanence va 
déjà de pair, chez Spinoza, avec un vocabulaire de la fluidité (le verbe effluere se lit dans la scolie de Ethique, I, I7) et avec un vocabulaire du pli (com-plicare, ex-plicare). Ce qui nous permet de faire une remarque, non seulement sur les flux et les plis deleuziens mais, déjà, sur nos petits dessins de Victor Hugo: c'est la même encre qui est utilisée, d'un côté avec la pointe de la plume pour dégager les aspects — un bateau, sur notre exemple (...) - , et d'un autre côté avec les barbes de la même plume (ou avec un pinceau) pour noyer les aspects dans cette espèce de turbulence fluide ou detourmente généralisée. Bref, l'encre est ici un milieu d'immanence qui réunit la forme avec l'informe, avec la matière, avec le contenu, avec le symbole et avec tout ce que vous trouverez encore sur ces dessins... Le philosophe "clair et distinct" pourra s'effrayer d'un tel mélange, sans doute. Mais il faut apprendre, avec les images, à penser toutes choses impures et intriquées (...) L'homme est destructible, l'homme est indestructible il faut penser cela ensemble. L'homme est destructible, réductible à l'informe. Mais sa destruction même laisse des traces qui, fussent-elles informes, requièrent de nos regards la mise question, donc la mise en jeu, de l'anthropomorphisme. Interroger chaque trace sous l'angle humain, voilà le problème d'une anthropologie du regard. Dissemblance avec ressemblance sinon la dissemblance devient une pure idée métaphysique, et la ressemblance une pure niaiserie înfraphysique. Nous ne cessons de peiner avec cette vérité la destruction n'est pas l'Autre absolu de l'humain, malheureusement. La destruction nous est immanente — travail contre travail (Èros contre Thanatos). Et l'image? Eh bien, l'image ne serait qu'un bout visuel à scruter attentivement, un pli, une boucle de vague dans cette immanence» (Didi-Huberman y Noudelmann).

${ }^{29}$ Ver Didi-Huberman: Devant le temps. Histoire de l'art et anachronisme des images, 2000; La imagen mariposa, 2007; La invención de la histeria. Charcoty la iconografia fotográfica de la Salpêtrière, 2007; La ressemblance par contact, 2008; L'image survivante. Histoire de l'art et temps des fantômes selon Aby Warburg, 2002; "L'immagine aperta» en Georges Bataille: il Politico e il Sacro, 1987; Ninfa moderna. Essai sur le drapé tombé, 2002; Lo que vemos, lo que nos mira, 1997; Venus rajada, 2005; Atlas.
¿Cómo llevar el mundo a cuestas?, 2010; Imágenes pese a todo. Memoria visual del Holocausto, 2004.

30 «Afferrare la Fortuna per il ciuffo è l'atto che si oppone nel modo più netto all'atteggiamento passivo nei confronti del fato e precisamente per il Rinascimento (ad esempio Petrarca, de remediis utriusque fortunae e credo anche Boccaccio) fino a Machiavelli questa $\mathrm{Oc}$ casio è la più decisa concorrente della Fortuna con la ruota e con la vela. (...) La medaglia rinascimentale che devi ricevere, di cui ti ho già scritto, mostra con un simbolismo assolutamente felice la "mentalità" dell'uomo rinascimentale. Un uomo armato di corazza afferra per il ciuffo la Fortuna con la vela —con l'iscrizione: Velis nolisve. Dunque con lo spiritoso gioco di parole, veliscon le vele, che tu lo voglia o no, e anche le tue vele non ti sono affatto d'aiuto. (...) Così è, da un lato, il timone, dall'altro il ciuffo della Fortuna il manico da afferrare (griffliche Handhabe) per colui che lotta con le potenze demoniche della vita. Esse vengono, nell'esser prese, comprese (durch Greifen begriffen). L'essenza del simbolo religioso pagano consiste, da un lato, nella causazione (Verursachung) antropomorfa delle cose in genere, al fine di comprendere il divenire, che fluisce in maniera enigmatica, come meta volontariamente perseguita di una personalità sovrumana. $\mathrm{E}$ in tal modo, dall'altro lato, il simbolo consente al credente di confrontarsi con questa causa dai sentimenti fondamentalmente umani attraverso la lotta, e non soltanto tramite preghiera e sacrificio. (...) La Fortuna con il ciuffo, che deriva dal Kairos, come supplemento alla biologia dei simboli del fato, (...) mostra il cosiddetto uomo moderno nella sua condizione di crescente insolenza» (Warburg:13-15).

${ }^{31}$ «Nella prospettiva dell'ideologia liberista oggi dominante. Il paradigma del mercato autoregolantesi si è sostituito a quello della giustizia e finge di poter governare una società sempre più ingovernabile secondo criteri esclusivamente tecnici. Ancora una volta, una società può funzionare solo se la giustizia (che corrisponde nella Chiesa, all'escatologia) non resta una mera idea, del tutto inerte e impotene di fronte al diritto e all'economia» (Agamben 2013:I8-19). Sobre la cuestión puede consultarse Prozorov «Giorgio Agamben and the End of History. Inoperative Praxis and the Interruption of the 
Dialectic», y Britt «The Schmittian Messiah in Agamben's The Time That Remains".

32 Para una lectura dialógica de la cuestión, ver Holquist «The place of philology in an age of world literature». Para una desconstrucción menos radical, Hillis Miller «How To (Un)Globe the Earth in Four Easy Lessons».

${ }^{33}$ Para la línea clã do jaboti, como la llamaría Mário de Andrade, ver Carl Einstein «On Primitive Art».
${ }^{34}$ Ver Hamacher, 2008; 20II; 20I2; Antelo, Archifilologías latinoamericanas (en prensa). Para una perspectiva positiva, McGann 2013.

${ }^{35}$ Para ese debate ver «Comparative Literature/World Literature: A Discussion with Gayatri Chakravorty Spivak and David Damrosch». Comparative Literature Studies, 455-485.

\section{Bibliografía}

Agamben, Giorgio (1970). L'uomo senza contenuto. Milán: Rizzoli. (200I). «Identificación y desidentificación de un autor llamado José Bergamin». Archipélago. Cuadernos de crítica de la cultura 46, 8I-87. (2007). Ninfe. Torino: Bollati Boringhieri.

(2008). Signatura rerum. Sul metodo. Torino: Bollati Boringhieri. (2013). Il mistero del male. Benedetto XVI e la fine dei tempi. Roma: Laterza.

Ahmed, Siraj (2013). «Notes from Babel: Toward a Colonial History of Comparative Literature». Critical Inquiry 2, 296-326.

Alemán, Jorge (2009). «Debate Ernesto Laclau/Jorge Alemán: ¿Por qué los significantes vacíos son importantes para la política?». Por una izquierda lacaniana. Buenos Aires: Grama, 89-III.

Antelo, Raúl (Ed.) (200I). Antonio Candido y los estudios latinoamericanos. Pittsburgh: Instituto Internacional de Literatura Iberoamericana.

(2003). "Crítica híbrida e forma histórica», en João Cezar de Castro Rocha, organizador. Nenhum Brasil existe - Pequena enciclopédia. Rio de Janeiro: Uerj/Univercidade/ Topbooks, 911-920.

Archifilologías latinoamericanas. Villa María: EDUvim. En prensa.

AvanCinI, José A. (1994). «Mário e o barroco». Revista do Instituto de Estudos Brasileiros 36, 47-66.

Ávila, Affonso (1994). O lúdico e as projęôes do mundo barroco. São Paulo: Perspectiva.

Belting, Hans (2005). «Image, Medium, Body: A New Approach to Iconology». Critical Inquiry 2, 302-319.

Bois, Yve-Alain; Hal Foster y David Joselit (2OII). «Recessional Aesthetics: an Exchange». October 135, 93-II6.

Borges, Jorge Luis (1940, in de febrero). «Algunos pareceres de Nietzsche». La Nación, 2da sección, I.

Brennan, Tімотнy (2010). «Running and Dodging: The Rhetoric of Doubleness in Contemporary Theory». New Literary History 2, 277-30I.

Britt, Brian (20I0). «The Schmittian Messiah in Agamben's The Time That Remains». Critical Inquiry 2, 262-287.

Cadava, Eduardo y Paola Cortes Roca (2005). «Re Jd: Remembering Jacques Derrida». Grey Room 20, 74-79. (2006). «Notes on Love and Photography». October II6, 3-34. 
Caillois, Roger (20I2). Piedras y otros textos. Madrid: Siruela. Traducción de Daniel Gutiérrez Martínez.

Campos, Haroldo de (1989). O Seqüestro do Barroco na formação da literatura brasileira: o caso Gregório de Mattos. Salvador: Fundação Casa de Jorge Amado.

Candido, Antonio (199i). Crítica Radical. Caracas: Biblioteca Ayacucho.

(1995). Ensayos y comentarios. México: Fondo de Cultura Económica.

Chaui, Marilena (2000). Brasil. Mito fundador e sociedade autoritária. São Paulo: Fundação Perseu Abramo.

Colebrook, Claire (2002). Gilles Deleuze. Londres: Routledge. (20II). "The Context of Humanism». New Literary History 4, 70I-7I8.

Collins, Douglas (2002-2003). «The Great Effects of Small Things: Insignificance With Immanence in Critical Theory» [en línea]. Anthropoetics 2. Consultado el 25 de septiembre de 2015 en http://www.anthropoetics.ucla.edu/apo8oz/collins.htm

Corbisier, Roland (1949, 4 dez). "Consciência e nação». «Letras e Artes». Suplemento do Jornal $A$ Manhã I46.

Déotte, Jean-Luis (2013). La época de los aparatos. Buenos Aires: Adriana Hidalgo.

Della Volpe, Galvano (1949). «Sulla genesi aristotelica della contraddizione». Actas del Primer Congreso Nacional de Filosofía. Universidad Nacional de Cuyo. Buenos Aires, 1950. (1966). Crítica del gusto. Barcelona: Seix Barral.

(1972). Historia del Gusto. Madrid: Alberto Corazón.

Dews, Peter (1987). Logics of Disintegration: Poststructuralism and the Claims of Critical Theory. Londres: Verso.

Díaz QuiÑones, ArCadio (1998). «Fernando Ortiz y Allan Kardec: espiritismo y transculturación». Prismas. Anuario de historia intelectual 2, I75-192.

Didi-Huberman, Georges (2009). Survivance des lucioles. París: Minuit.

Didi-Huberman, Georges y François Noudelmann (2002). «Image, matière: immanence». Rue Descartes 38, 86-99.

Einstein, Carl (2003). "On Primitive Art». October I05, I24.

Foster, Hal (2008). Dioses prostéticos. Madrid: Akal.

Foucault, Michel (1994). Dits et écrits. París: Gallimard.

(1999). «Polémica, política y problematizaciones». Estética, ética y hermenéutica.

Obras esenciales. Vol. III. Barcelona: Paidós, 353-26r. Traducción de Ángel Gabilondo.

Gerbaudo, Analía (20I2). «Sobre la dicha de tener polémicas». Estudios de Teoría Literaria 2, 83-98. Gruzinski, Serge (2000). El pensamiento mestizo. Barcelona: Paidós.

Gumbrecht, Hans-Ulrich (2004). En igz6: viviendo al borde del tiempo. México: Universidad Iberoamericana. (2013). After 1945. Latency as Origin of the Present. Stanford University Press.

Hamacher, Werner (2008). Heterautonomien: One 2 Many Multiculturalisms. Diaphanes. (201I). 95 tesis sobre la Filología. Buenos Aires: Miño y Dávila, Traducción de Laura Carugatti. (20I2). Lingua amissa. Buenos Aires: Miño y Dávila.

Hiluis Miller, Joseph (20I2) «How To (Un)Globe the Earth in Four Easy Lessons». SubStance I, I5-29. 
Hollier, Denis (1993). De la littérature française. París: Bordas.

Holquist, Michael (20II). «The place of philology in an age of world literature». Neohelicon $38,267-287$.

Huyssen, Andreas (2006). Después de la gran división. Modernismo, cultura de masas, posmodernismo. Buenos Aires: Adriana Hidalgo. Traducción de Pablo Gianera.

Krauss, Rosalind (2010). "The Angel of History». October I34.

Laclau, Ernesto (1996). Emancipación y diferencia. Buenos Aires: Ariel.

(2000). Misticismo, retórica y politica. Buenos Aires: Fondo de Cultura Económica. (2005). La razón populista. Buenos Aires: Fondo de Cultura Económica. (2008). Debates y combates. Por un nuevo horizonte de la politica. Buenos Aires: Fondo de Cultura Económica.

(20II). «Conversaciones filosóficas. Entrevista con Etienne Balibar y Ernesto Laclau». Debates y combates I, 29-3I.

LaXton, Susan (2012). «As Photography: Mechanicity, Contingency, and Other-Determination in Gerhard Richter's Overpainted Snapshots». Critical Inquiry 4, 776-795.

Löwith, Karl (1950). «Implicaciones teológicas de la filosofía de la historia». Actas del Primer Congreso Nacional de Filosofía. Universidad Nacional de Cuyo/Buenos Aires.

Ludueña Romandini, Fabián (20I3). "(Más allá de) la hantología: ¿es posible una (post-) metafísica de la espectralidad?», en AA. Vv. Derrida político. Buenos Aires: Colihue, I45-158.

McGann, Jerome (2013). «Philology in a New Key». Critical Inquiry 2, 327-346.

Meillassoux, Quentin (2006). "Deuil à venir, dieu à venir». Critique 704/705, I05-II5.

Menendez Pelayo, Marcelino (1948). Historia de la Poesía Hispano-americana. Vol. II. Madrid: Consejo Superior de Investigaciones Científicas.

Mitchell, William J. Thomas (20I2). «Image, Space, Revolution: The Arts of Occupation». Critical Inquiry I, 8-32.

Monahan, Laurie (2004). «Rock Paper Scissors». October 107, 95-II4.

Prozorov, Sergei (2009). «Giorgio Agamben and the End of History. Inoperative Praxis and the Interruption of the Dialectic». European Journal of Social Theory 4, 523-542.

RabatÈ, JeAn-Michel (20IO). Etant donnés: $I^{\circ}$ l'art, $2^{\circ}$ le crime - La modernité comme scène $d u$ crime. Dijon: Les presses du réel.

Rama, Ángel (1982). Transculturación narrativa en América Latina. México: Siglo XXI.

Richter, Gerhard (200I). Survey. Stuttgart/Cologne: Institut für Auslandsbeziehungen/ Walther König. Texto de Dieter Schwarz.

Romagosa, Carlos (1897). Joyas poéticas americanas. Córdoba: La Minerva.

Schwarz, Roberto (1970). "Remarques sur la culture et la politique, au. Brésil - 1964/1969». Les Temps Modernes 288, 37-73.

- (1972). «Dépendance nationale, déplacement d'idéologies, littérature: sur la culture brésilienne au xixème siècle». L Homme et la société 26, 99-IIO. (1992). «Cultura e Política: 1964-1969». O Pai de Família e Outros Estudos. São Paulo: Paz e Terra, 6I-92.

(1999). Sequências brasileiras. São Paulo: Companhia das Letras.

Sloterdijk, Peter (2007). En el mundo interior del capital. Para una teoría filosófica de la globalización. Madrid: Siruela. Traducción de Isidoro Reguera. 
VAlÈry, Paul (1957). «Polémistes», en Jean Hytier, editor. Oeuvres Completes I. París: Gallimard. Vattimo, Gianni (1988). As aventuras da diferença. Lisboa: Ediçóes 70.

Warburg, Aby (2009). Per monstra ad sphaeram. Davide Stimilli, editor. Milano: Abscondita. 